ARTICLE

Received 7 Feb 2012 | Accepted 13 Nov 2012 | Published 18 Dec $2012 \quad$ DOl: 10.1038/ncomms2282

\title{
Delivery of chemotherapeutic drugs in tumour cell-derived microparticles
}

Ke Tang ${ }^{1,2, \star}$, Yi Zhang ${ }^{1, \star}$, Huafeng Zhang ${ }^{1}$, Pingwei $\mathrm{Xu}^{1}$, Jing Liu ${ }^{1}$, Jingwei Ma ${ }^{3}$, Meng Lv , Dapeng Li ${ }^{1}$, Foad Katirai ${ }^{1}$, Guan-Xin Shen ${ }^{3}$, Guimei Zhang ${ }^{1}$, Zuo-Hua Feng ${ }^{1}$, Duyun $\mathrm{Ye}^{2} \&$ Bo Huang ${ }^{1,4}$

Cellular microparticles are vesicular plasma membrane fragments with a diameter of 100-1,000 nanometres that are shed by cells in response to various physiological and artificial stimuli. Here we demonstrate that tumour cell-derived microparticles can be used as vectors to deliver chemotherapeutic drugs. We show that tumour cells incubated with chemotherapeutic drugs package these drugs into microparticles, which can be collected and used to effectively kill tumour cells in murine tumour models without typical side effects. We describe several mechanisms involved in this process, including uptake of drug-containing microparticles by tumour cells, synthesis of additional drug-packaging microparticles by these cells that contribute to the cytotoxic effect and the inhibition of drug efflux from tumour cells. This study highlights a novel drug delivery strategy with potential clinical application.

\footnotetext{
${ }^{1}$ Department of Biochemistry and Molecular Biology, Tongji Medical College, Huazhong University of Science and Technology, Wuhan 430030, China. ${ }^{2}$ Department of Pathophysiology, Tongji Medical College, Huazhong University of Science and Technology, Wuhan 430030, China. ${ }^{3}$ Department of Immunology, Tongji Medical College, Huazhong University of Science and Technology, Wuhan 430030, China. ${ }^{4}$ National Key Laboratory of Medical Molecular Biology and Department of Immunology, Chinese Academy of Medical Sciences, Beijing 100730, China. * These authors contributed equally to this work. Correspondence and requests for materials should be addressed to B.H. (email: tjhuangbo@hotmail.com).
} 
T he selective delivery of chemotherapeutic drugs to tumour cells is a major challenge in cancer chemotherapy. Recent studies show that packaging clinically approved drugs into nanoscale vesicular vehicles $(10-100 \mathrm{~nm}$ in diameter) can effectively deliver chemotherapeutic drugs to tumour sites, leading to improved pharmacokinetic efficiency and therapeutic efficacy ${ }^{1,2}$. Nonetheless, these drug-loaded artificial nanoparticles have several disadvantages. First, nanometre-scale materials, as nonself components, are usually toxic and may cause adverse effects, for example, by activating oxidative stress pathways ${ }^{2-7}$; second, micelles are of inadequate stability in the blood stream; third, co-encapsulation of more than one drug can result in batch-to-batch variability in the drug load; and fourth, the cost of assembly of nanoparticles is expensive, especially if they contain engineered antibodies or aptamers. Notwithstanding these defects, the development of advanced nanoparticle drug carriers is currently vigorously pursued in the field of cancer therapeutics ${ }^{1,7}$. However, one facet or direction, often overlooked, is the existence and efficacy of natural counterparts to these artificial nanoparticles.

Cells are capable of generating various vesicles of different sizes but whether these cell-derived microvesicles are suitable for drug delivery remains unclear. In response to various stimuli, cells may change their cytoskeletal structure and result in the encapsulation of cytosolic elements by the plasma membrane that are then released into the extracellular space. These specialized subcellular vesicles with a diameter of $100-1,000 \mathrm{~nm}$ are called microparticles (MPs) ${ }^{8,9}$. Wolf first observed MPs from activated blood platelets in 1967 and described them as pro-coagulant 'dust' ${ }^{\text {' }}$. Since then, it has progressively become more evident that MPs can be derived from almost all cell types and have crucial roles under physiological or pathophysiological conditions ${ }^{8,11}$. MPs not only contain messenger molecules, enzymes, RNAs and even DNA, but also are capable of transferring these bioactive molecules from one cell to another ${ }^{12-15}$. Thus, functionally, MPs appear to act as vectors delivering molecular messages between cells. Considering these similarities of MPs with nanoparticles in size, structure and vector function, it is reasonable to hypothesize that MPs may be useful as endogenous natural vehicles to deliver chemotherapeutic drugs.

This study demonstrates that MPs, derived from apoptotic tumour cells, can package and deliver chemotherapeutic drugs to tumour cells, thereby, leading to the timely death of the tumour cells without typical drug-associated side effects.

\section{Results}

Development of tumour cell-derived drug-encapsulating MPs. We first tested whether apoptotic tumour cells, induced by chemotherapeutic drugs, could produce drug packaging MPs. For this purpose, carboxyfluorescein succinimidyl ester (CFSE)stained mouse hepatocarcinoma tumour cell line H22 were incubated with $10 \mu \mathrm{g} \mathrm{ml}^{-1}$ methotrexate (MTX) and then irradiated with ultraviolet light for further apoptosis induction. The MPs were isolated ${ }^{16,17}$, and analysed by flow cytometry. Apoptotic tumour cells could indeed release considerable MPs (Fig. 1a, left). As large as $3 \times 10^{5}$ MPs were yielded from $5 \times 10^{6}$ tumour cells (Fig. 1a, right). These MPs were not generated owing to background noise or nonspecific events (Supplementary Fig. S1), and showed membrane structures with 100-1,000-nm sizes as judged by electron microscopy (Fig. 1b). Such membrane structures were further confirmed by western blot (Supplementary Fig. S2) and by flow cytometric analysis of MPs derived from Raw 264.7 cells (Supplementary Fig. S3). Given the fluorescent nature of doxorubicin ${ }^{18}$, we employed doxorubicin fluorescence to determine whether the drug is packaged into the released MPs. Doxorubicin was clearly shown to be encapsulated by MPs (Fig. 1c). Moreover, high-performance liquid chromatography (HPLC) analysis showed that the different concentrations of doxorubicin or MTX in MPs were owing to drug doses (Fig. 1d, Supplementary Fig. S4). Besides H22 cells, the human ovarian cancer tumour cell line A2780 also produced MPs after the treatment by cisplatin (Fig. 1a) or doxorubicin (Fig. 1c), suggesting that tumour cells may indeed generate drugencapsulating MPs in response to chemotherapeutic treatments.

Tumour cell-derived drug-encapsulating MPs are cytotoxic. To verify whether drug-encapsulating MPs are cytotoxic to tumour cells, low or high concentrations of MTX $\left(1\right.$ or $\left.10 \mu \mathrm{g} \mathrm{ml}^{-1}\right)$ were added to the cultured $\mathrm{H} 22$ cells $\left(5 \times 10^{6}\right) 1 \mathrm{~h}$ before ultraviolet irradiation. After $12 \mathrm{~h}$, the released MTX-encapsulating MPs were incubated with $\mathrm{H} 22$ cells. Both high and low concentrations of MTX-MPs could induce tumour cell death after 48 or $72 \mathrm{~h}$ (Fig. 1e, Supplementary Fig. S5). Consistently, the higher drug dosage resulted in MP packaging more drug molecules. MPs from $100 \mu \mathrm{g} \mathrm{ml}^{-1}$ doxorubicin-treated H22 cells showed much stronger mean fluorescence intensity (MFI) than that from $10 \mu \mathrm{g} \mathrm{ml}^{-1}$ doxorubicin-treated $\mathrm{H} 22$ cells (1,316 versus 623). In addition, other drugs, such as cisplatin and hydroxyl camptothecin, and other cell lines, including A2780, B16, HL60 and EL4, were also tested, and the generated drug-packaging MPs also resulted in the similar results. Interestingly, the addition of MPs, generated from $1 \mu \mathrm{g}$ MTX-treated H22 tumour cells, cultured in $1 \mathrm{ml}$ medium, resulted in obviously discernible tumour cell killing, whereas the addition of $0.05 \mu \mathrm{g}$ MTX to the same culture media had no discernible cytotoxic effect (Fig. 1e, Supplementary Fig. S5). Furthermore, $0.6 \mu \mathrm{g}$ MTX only killed around 2\% H22 tumour cells in a $1 \mathrm{ml}$ medium, whereas MPs packaging $0.6 \mu \mathrm{g}$ MTX (based on HPLC results) induced around 23\% tumour cell death (Supplementary Fig. S6), suggesting that tumour cell-derived drug-encapsulating MPs might have a higher tumour-killing efficacy or efficiency than conventional chemotherapeutic drugs.

To further assess this pharmacological efficacy, the stability of MPs was tested. We found that doxorubicin-encapsulating MPs were at least stable for 1 week at $4{ }^{\circ} \mathrm{C}$ (Fig. 1f,g), and such stored MPs possessed a similar capability to kill H22 cells (Fig. 1e). In addition, MPs were found to be resistant to acidic and alkaline environments, light, shaking and high temperatures (room temperature or $37^{\circ} \mathrm{C}$ ), but not to SDS or proteinase $\mathrm{K}$ (Supplementary Fig. S7). As MPs were generated from apoptotic tumour cells, we also analysed cell death molecules by using western blot or DNA gel. Consistent with the previous report ${ }^{19}$, we found that MPs contained a panel of natural biomolecules, such as cytochrome c, caspases 3 and 9 , histones and DNA pieces (Supplementary Fig. S8). Together, these findings demonstrated that tumour cell-derived MPs are indeed capable of encapsulating chemotherapeutic drug, are cytotoxic to tumour cells and more effective than direct treatment with the same drug on a doseper-dose basis.

MTX-encapsulating MPs inhibit ascites hepatocarcinoma growth. To address whether MPs could be used for anticancer therapy in vivo, we injected MTX-encapsulating MPs intravenously (i.v.) or intraperitoneally (i.p.) into mice. Two milligram MTX were added to $2 \mathrm{ml}$ culture media with $2 \times 10^{7} \mathrm{H} 22$ tumour cells $1 \mathrm{~h}$ before ultraviolet irradiation. Each of the prepared MPs was then used for one mouse per package. Collectively, mice were treated once per day for 6 days. Compared with simple MPs or PBS control, MTX-MPs did not induce any hair and/or weight changes in the mice or adversely affect liver or kidney functions (Fig. 2a). In contrast, twice repeated i.v. or i.p. injections of 
a

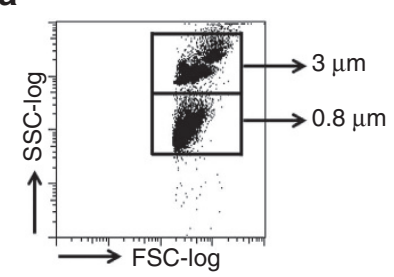

b
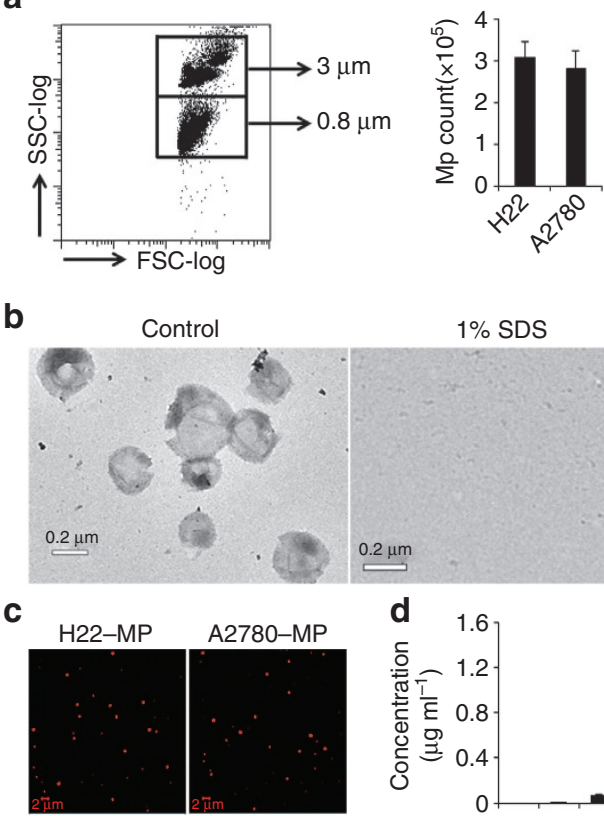

$1 \%$ SDS
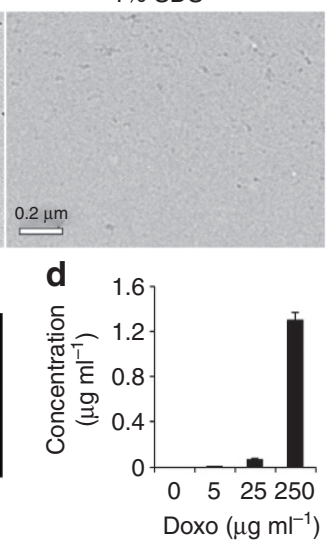

e

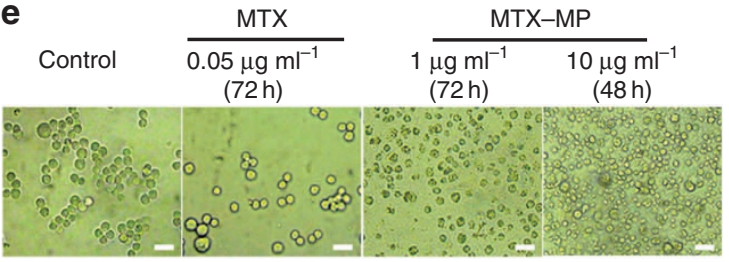

f

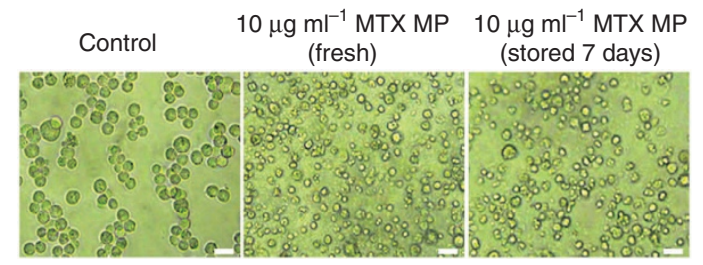

g

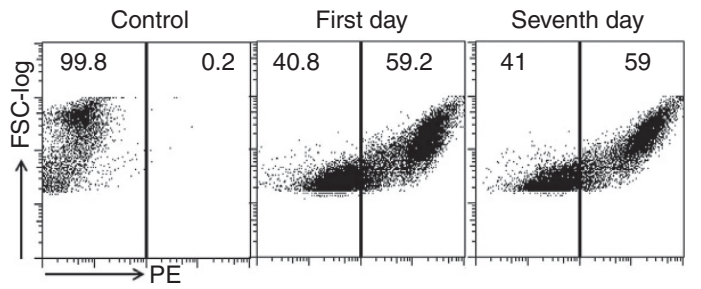

Figure 1 | MPs are cytotoxic after encapsulating chemotherapeutic drugs. (a) Apoptotic tumour cells released a large number of MPs. CFSE-labelled H22 cells $\left(5 \times 10^{6}\right)$ were incubated with $10 \mu \mathrm{g} \mathrm{ml}{ }^{-1} \mathrm{MTX}$ and irradiated with ultraviolet B. After $12 \mathrm{~h}, \mathrm{MPs}$ were isolated and counted by a flow cytometer on the basis of $0.8 \mu \mathrm{m}$ beads (left). Data are the representative of three independent experiments. Bars correspond to mean \pm s.d. (b) MPs treated with or without $1 \%$ SDS were analysed by transmission electron microscope. (c) Tumour cells treated with chemotherapeutic drugs released drug-packaging MPs. H22 cells or A2780 cells were incubated with $100 \mu \mathrm{g} \mathrm{ml}^{-1}$ doxorubicin and irradiated with UBV. MPs were isolated and observed under two-photon laser scanning fluorescence microscope. Doxorubicin was shown as the red colour. Scale bar, $2 \mu \mathrm{m}$. (d) The concentration of doxorubicin in MPs was measured by HPLC. Data are the representative of three independent experiments. Bars correspond to mean \pm s.d. (e) Drug-encapsulating MPs were cytotoxic to tumour cells. MTX $\left(1\right.$ or $\left.10 \mu \mathrm{g} \mathrm{ml}^{-1}\right)$ was added to $\mathrm{H} 22$ tumour cells $\left(5 \times 10^{6}\right)$ for $1 \mathrm{~h}$ and then treated with UBV. After isolation $12 \mathrm{~h}$ later, half of MTXencapsulating MPs were incubated with $\mathrm{H} 22$ tumour cells. The death of tumour cells was observed at different time points. $\mathrm{H} 22$ cells treated with $0.05 \mu \mathrm{g} \mathrm{ml}{ }^{-1}$ MTX were observed after $72 \mathrm{~h}$. Scale bar, $25 \mu \mathrm{m}$. (f,g) Chemotherapeutic drug-encapsulating MPs were stable. MPs from MTX-treated H22 tumour cells were stored at $4{ }^{\circ} \mathrm{C}$ for 7 days, and then added to $\mathrm{H} 22$ cell culture medium for cytotoxicity assay. Scale bar, $25 \mu \mathrm{m}$ (f). MPs from doxorubicintreated $\mathrm{H} 22$ cells or untreated cells as control were stored at $4{ }^{\circ} \mathrm{C}$ for 7 days and the stability of these MPs was analysed by flow cytometry (g). MPs without doxorubicin served as control and doxorubicin-packaging MPs were reflected by the positive dot plots. In this figure, 10,000-20,000 events were collected for flow cytometric analysis.
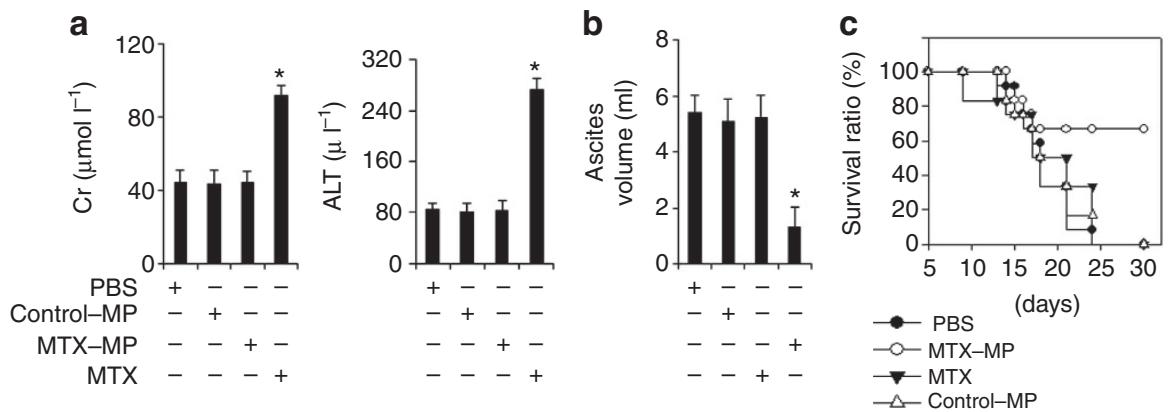

Figure 2 | MTX-packaging MPs inhibit peritoneal $\mathbf{H 2 2}$ cell growth without typical side effects. (a) MTX-encapsulating MPs did not adversely impact liver or kidney functions. $2 \times 10^{7} \mathrm{H} 22$ cells were incubated with $2 \mathrm{mg} \mathrm{MTX}$ in $2 \mathrm{ml}$ culture medium for $1 \mathrm{~h}$ before ultraviolet irradiation, and the isolated MPs were injected i.v. or i.p. to one mouse once per day for 6 days ( $n=8$ for each group). Serum levels of glutamic-pyruvate transaminase and creatinine were detected. MPs from sole UBV-treated H22 cells and the two time injection of $2 \mu \mathrm{g} \mathrm{g}^{-1}$ MTX were used as controls. Bars correspond to mean \pm s.d. The data shown were representative of three reproducible experiments. (b,c) MTX-MPs inhibited tumour growth. H22 cells were i.p. injected mice ( $n=12$ for each group). On day 1, MPs from $1 \mathrm{mg} \mathrm{ml}{ }^{-1}$ MTX-treated $\mathrm{H} 22$ cells or UBV-treated cells were i.p. injected to the mice once per day for 10 days. Or, single MTX $\left(0.5 \mu \mathrm{g} \mathrm{g}^{-1}\right)$ was i.p. injected to mice once per day for 5 days. On day 11, half the mice in each group were killed and the volume of ascites was measured (b). The rest of the mice were used for long-term survival observation (c). Data are representative of three independent experiments. $P<0.001, M T X . M P$ group compared with PBS control group.

$2 \mu \mathrm{gg}^{-1}$ MTX produced typical side effects (Fig. 2a). We then assessed the therapeutic efficacy of MTX-packaging MPs in a murine hepatocarcinoma ascites model. The i.p. injection of H22 cells formed obvious ascites within 10 days. The next day after the i.p. tumour cell inoculation, the mice were given treatments of MPs once per day for 5 days. On day 10, the mice were killed and 

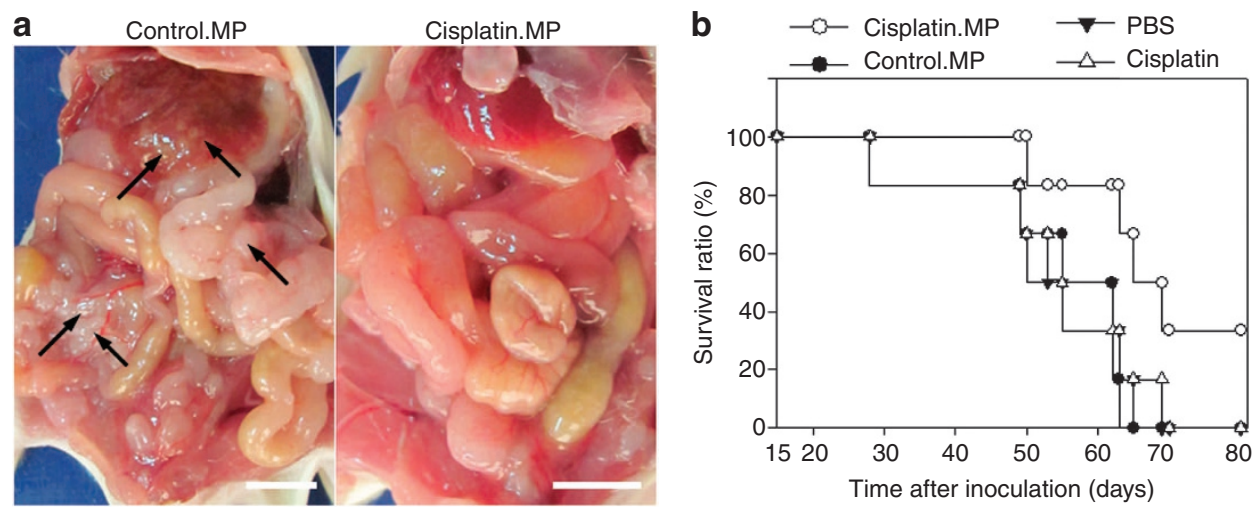

Figure 3 | Cisplatin-packaging MPs inhibit ovarian cancer growth in SCID mice. (a,b) A2780 cells were i.p. injected to SCID mice ( $n=12$ per group). From the next day, mouse was administered with MPs or with single cisplatin $\left(2 \mu \mathrm{g} \mathrm{g}^{-1}\right)$ or PBS by i.p. injection once per day for continuous 5 days. After 14 days, an additional treatment was administered once per day for 5 days. After 30 days, half the mice were killed and the tumour nodes were observed. The typical nodes were shown by the arrow. Scale bar, $1 \mathrm{~cm}$. (a). The remaining mice were used for the long-term survival observation (b). Data are representative of three independent experiments. $P<0.001$, Cisplatin.MP group compared with PBS control group.

the volume of ascites measured. The results showed that the volume of ascites was significantly reduced in the mice treated with MTX-MPs compared with control groups (Fig. 2b). Consistently, MTX-MPs-treated mice had much longer survival time (Fig. 2c), clearly suggesting that MTX-encapsulating MPs inhibit tumour growth without typical side effects in a murine hepatocarcinoma ascites model.

Cisplatin-encapsulating MPs inhibit ovarian cancer growth. To further confirm that tumour cell-derived chemotherapeutic drugencapsulating MPs have an anticancer activity, human ovarian cancer in severe combined immunodeficient (SCID) mice was also tested by i.p. injection of A2780 cells. Six hundred micrograms cisplatin was added to 2 -ml culture media with $2 \times 10^{7}$ A2780 cells $1 \mathrm{~h}$ before ultraviolet irradiation. The MPs formed were then used for one mouse each. Similar to the above MTX-MPs, the administration of cisplatin-MPs continuously for 5 days did not affect liver and kidney functions of SCID mice either. In order to test their therapeutic efficacy, cisplatin-MPs were administered to mice 5 days after A2780 cell inoculation. After 14 days, an additional treatment was administered once per day for 5 days. After 30 days, SCID mice were killed and the tumour growth evaluated. As shown in Fig. 3a, almost no tumour nodes were observed in the cisplatin-MP group. In contrast, a large number of tumour nodes was seen in control-MP group. Consistently, cisplatin-MP-treated mice had much longer survival times (Fig. 3b). Moreover, MPs packaging cisplatin and paclitaxel almost completely suppressed A2780 tumour growth in nude mice (Supplementary Fig. S9). Therefore, A2780 cell-derived MPs inhibit human ovarian cancer growth in SCID mice by packaging cisplatin or cisplatin/paclitaxel.

Tumour cells take up chemotherapeutic drug-packaging MPs. To elucidate the mechanism by which drug-encapsulating MPs efficiently mediate tumour cell killing, we first asked whether the interaction between MPs and tumour cells were required for tumour cell killing. MTX-MPs were incubated in culture media for $48 \mathrm{~h}$ and separated from the media by centrifugation. Interestingly, only the separated MTX-MPs, but not the corresponding supernatants or the supernatants from the last MPs washing, were cytotoxic (Fig. 4a), suggesting that chemotherapeutic drugs are within and not discharged from MPs. This was in line with the previous result of Fig. 1d, which showed that MPs were very stable. Here, it was further observed that MPs were Triton X-100 resistant (Fig. 4b, Supplementary Fig. S7), hinting a direct interaction between tumour cells and MPs. In addition, MPs derived from CFSE-stained H22 cells were incubated with PKH26-stained $\mathrm{H} 22$ cells. It was found that the green MPs were efficiently taken up by red $\mathrm{H} 22$ cells (Fig. 4c) and around 54\% H22 cells took up MPs (Fig. 4d). To test this result in vivo, doxorubicin-packaging MPs were i.p. injected into mice that previously received an injection of $\mathrm{H} 22$ cells. About $11.8 \%$ of the tumour cells were found red fluorescent and most of these red cells could be stained with Annexin V, the marker of cellular apoptosis (Fig. 4e). In parallel, after the injection of MTX-packaging MPs to mice peritoneal H22 tumour for 5 days, peritoneal immune cells were isolated for apoptotic analysis. As shown in Fig. 4f, drugpackaging MPs effectively induced the apoptosis of $\mathrm{F} 4 / 80^{+}$ macrophages but had no effect on $\mathrm{CD}^{+}{ }^{+} \mathrm{T}$ or $\mathrm{CD} 19^{+} \mathrm{B}$ cells. Consistently, H22 MPs were strongly taken up by $\mathrm{H} 22$ cells, but not by $\mathrm{T}$ or B cells in vitro (Supplementary Fig. S10a,b). As H22 cells are hepatocyte derived, primary liver cells were additionally assessed to take up MPs. It was found that the drug-packaging MPs were weakly taken up by and had minor effect on the primary liver cells (Supplementary Fig. S11a,b), suggesting that MPs are efficiently taken up by tumour cells.

Efficiency of MP-mediated drug delivery. To clarify whether drugs within MPs are delivered more efficiently to tumour cells than those not packaged into MPs, MPs from 100- $\mu$ g doxorubicin-treated $1 \times 10^{7}$ tumour cells in 4-ml culture media were prepared, and then $10 \%$ of the prepared MPs and the corresponding $10 \mu \mathrm{g}$ doxorubicin were added to $1 \times 10^{7}$ tumour cells in 4-ml fresh media, respectively. After $4 \mathrm{~h}$, cells were collected for flow cytometric analysis. In the MP group, tumour cells effectively took up MPs and showed strikingly high fluorescence. In contrast, in the 10- $\mu$ g doxorubicin group, although tumour cells showed positive fluorescence the relative intensity was much weaker (Fig. 4g). To clarify whether MPs have the same efficiency in vivo, doxorubicin-packaging $\mathrm{MPs}$ and the same dosecontaining doxorubicin as MPs (according to HPLC results) were i.p. injected into mice that previously received an injection of $\mathrm{H} 22$ tumour cells. After $12 \mathrm{~h}$, peritoneal tumour cells were isolated and detected by flow cytometry. The result showed that compared with simple drug administration, MPs resulted in an eightfold increase in the delivery efficiency of doxorubicin to tumour cells 
a

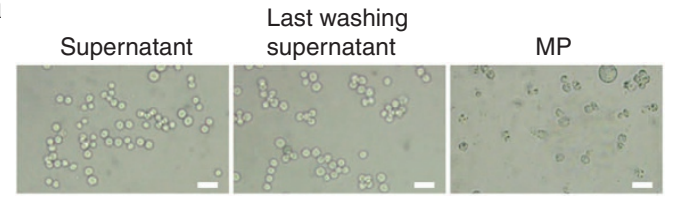

b
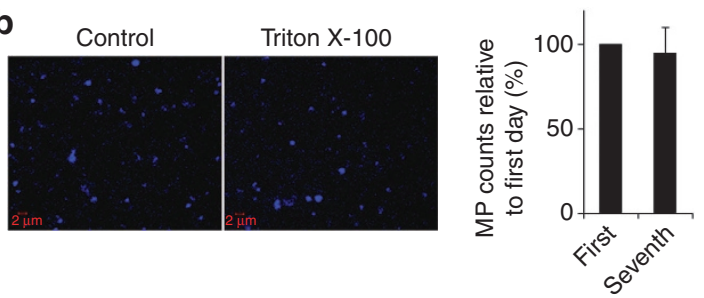

C

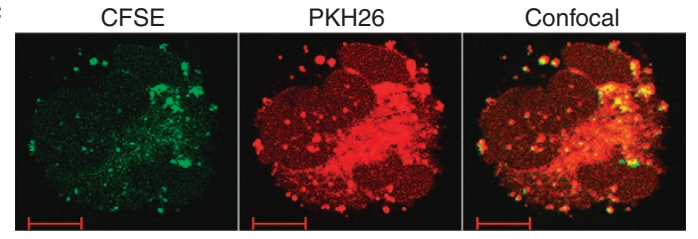

d

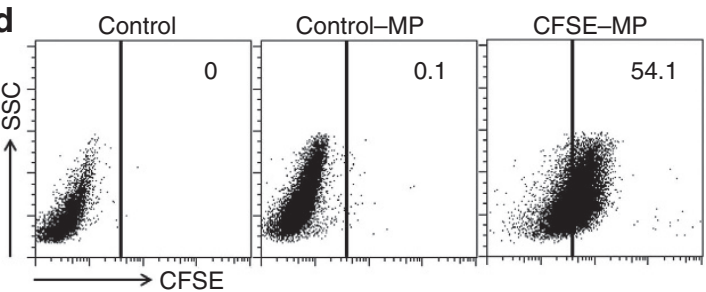

e
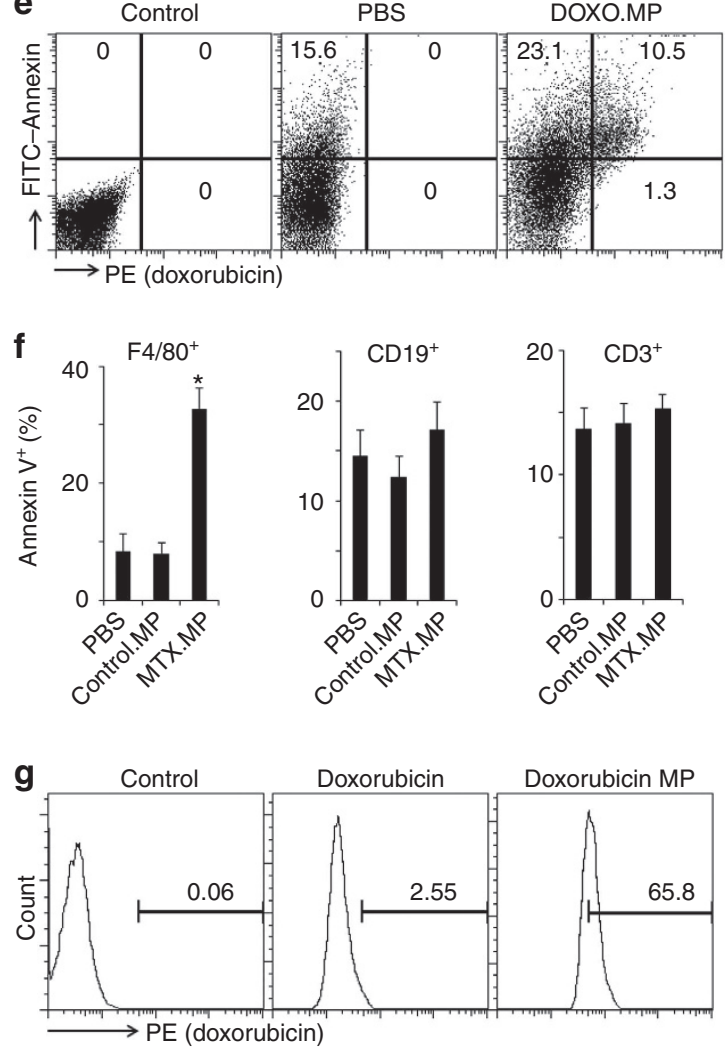

Figure 4 | MPs efficiently deliver chemotherapeutic drug molecules into tumour cells. (a) H22 cells were treated with $100 \mu \mathrm{g}$ MTX. After separation by centrifugation, MTX-MPs, the corresponding supernatants or the supernatants from the last MPs washing were co-cultured with $\mathrm{H} 22$ cells. After $48 \mathrm{~h}$, the tumour cell killing was observed. Scale bar, $25 \mu \mathrm{m}$. (b) MPs were resistant to Triton X-100. MPs from H22 cells were treated with or without $0.5 \%$ Triton $\mathrm{X}-100$ for $12 \mathrm{~h}$ and then incubated with Hoechst 33342. After $12 \mathrm{~h}$, MPs were isolated for the observation under a fluorescence microscope (left) or counted by a flow cytometer (right). Bars correspond to mean \pm s.d. Data are representative of three independent experiments. Scale bar, $2 \mu \mathrm{m}$. (c,d) H22 cells took up MPs. MPs isolated from CFSE (green)-labelled H22 cells were incubated with PKH 26 (red)-stained H22 cells. After 20 h, cells were observed under two-photon laser scanning fluorescence microscope, (c), or analysed by flow cytometry (d). Data are representative of three reproducible independent experiments. Scale bar, $10 \mu \mathrm{m}$. (e) Doxorubicin-packaging MPs were i.p. injected into mice, to which H22 cells were i.p. injected $24 \mathrm{~h}$ before. Twenty-four hours after MP injection, peritoneal tumour cells were isolated and stained with FITC-Annexin $V$ for flow cytometric analysis. (f) MPs isolated from MTXtreated or -untreated $\mathrm{H} 22$ cells were i.p. injected to mice $(n=6)$. After 5 days injection, peritoneal immune cells were isolated and stained with PEconjugated Annexin V and FITC-conjugated anti-F4/80, CD19 or CD3 antibody. The cells were analysed by flow cytometry. Bars correspond to mean \pm s.d. ${ }^{\star} P<0.05$, compared with control. (g) MPs improved the delivery efficiency of chemotherapeutic drug to tumour cells. The details were described in the Result part and Methods. In this figure, 10,000 events were collected for flow cytometric analysis.

(Supplementary Fig. S12). Taken together, these data suggest that MPs may concentrate the dispersive chemotherapeutic drug molecules and directly deliver them to tumour cells.

Drug-encapsulating MPs induce domino-like tumour cell killing. The concentration of drugs in tumour cells may explain why tumour cells were killed by MPs. However, it left unexplained why relatively few MPs could kill many tumour cells, as shown in Fig. 1. One possibility was that tumour cells killed by MTX-MPs form new MTX-packaging MPs, which are also cytotoxic. To test this hypothesis, H22 cells were incubated with MTX-MPs. After washing, tumour cells were put into new culture media and the new MPs were isolated. As expected, the second generation of MPs also induced H22 tumour cell death (Fig. 5a). As additional corroboration, when $\mathrm{H} 22$ tumour cells were treated with doxorubicin, it was found that doxorubicin was included in the second generation of MPs (Fig. 5b). Moreover, the third generation of MPs still contained the original drug and had cytotoxic activity against H22 cells (Fig. 5a,b).
Thus, chemotherapeutic drug-encapsulating MPs may generate a domino-like tumour killing effect.

Tumour cell-derived MPs impede drug efflux. To further elucidate MP-mediated killing efficiency, we turned our attention to whether MPs acted as a biomaterial that influences drugmediated tumour cell killing. MPs were found to be resistant to the effects of Triton X-100 (Fig. 4b), suggesting that lipid raft structure is involved in membrane origination of MPs. Interestingly, lipid rafts are known to be connected to drug efflux ${ }^{20-22}$, begging the question whether MPs might influence drug efflux in tumour cells. Therefore, H22 tumour cells were incubated with $\mathrm{H} 22$ tumour cell-derived MPs for $12 \mathrm{~h}$, followed by the addition of $0.8 \mu \mathrm{g} \mathrm{ml}^{-1}$ doxorubicin for $6 \mathrm{~h}$, and then the supernatant was replaced with the fresh medium for another 6-h culture. The drug efflux by tumour cells was then evaluated by flow cytometric analysis of intracellular fluorescent intensity. The results in the form of a decrease of MFI from 1,377 to 593 showed that H22 cells can effectively evacuate doxorubicin within 6h (Fig. 6a). 
a

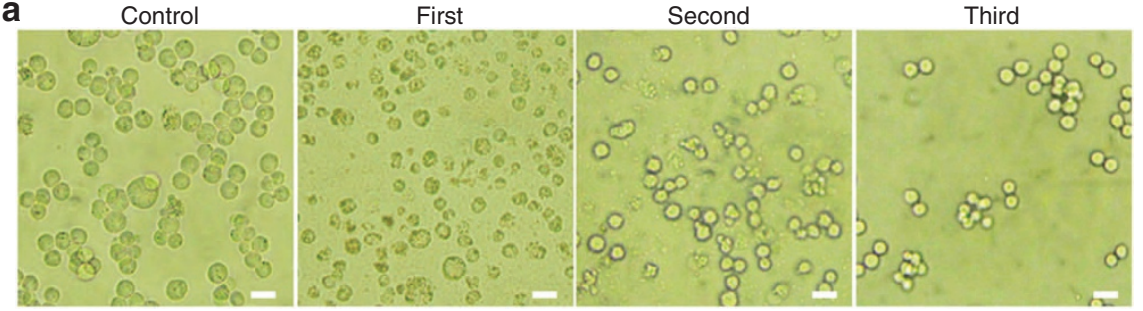

b

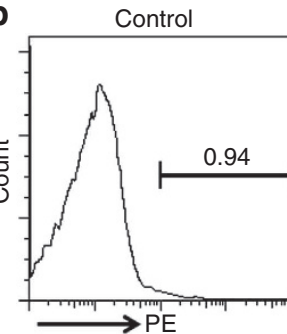

First

Second

Third

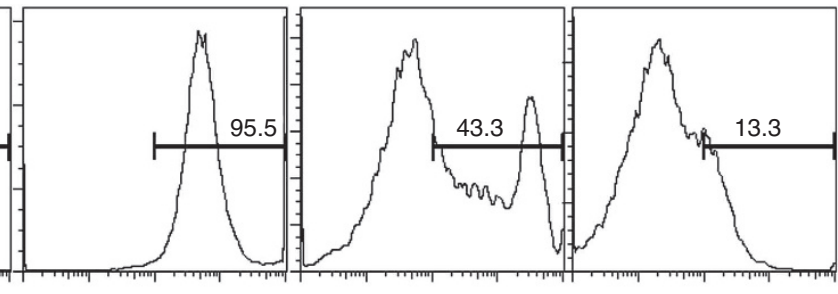

Figure 5 | Drug-containing MPs induce the formation of additional drug-packaging MPs. (a) MPs isolated from $1 \mathrm{mg} \mathrm{ml}^{-1} \mathrm{MTX}^{-t r e a t e d} 5 \times 10^{7} \mathrm{H} 22$ cells were designated as the first generation. These MPs were added to $1 \times 10^{7} \mathrm{H} 22$ tumour cells and washed out with fresh culture medium $6 \mathrm{~h}$ later, from which the generated MPs were called second generation of MPs. In the same way, a third generation of MPs was obtained. These three generations of MTX-packaging MPs were incubated with $1 \times 10^{5} \mathrm{H} 22$ cells, respectively, for $48 \mathrm{~h}$ and the tumour cell death was observed. Scale bar, $25 \mu \mathrm{m}$. (b) Red fluorescent intensity of three generations of doxorubicin-packaging MPs was measured by flow cytometry. Ten thousand events were collected for this analysis and data were representative of three reproducible independent experiments.
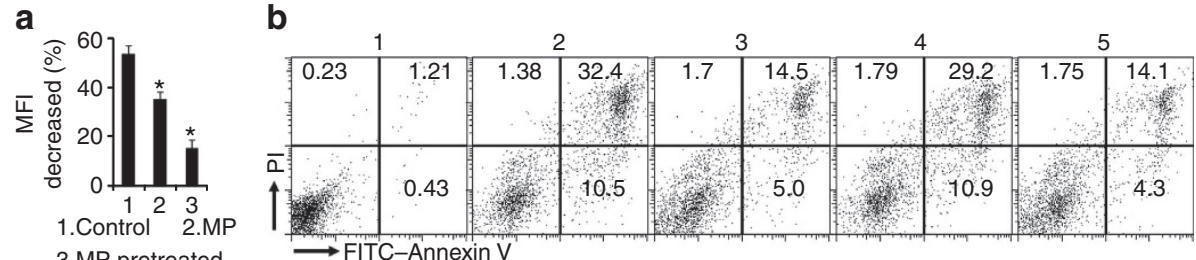

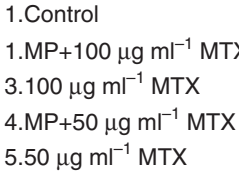

$5.50 \mu \mathrm{g} \mathrm{ml}^{-1} \mathrm{MTX}$

3.MP pretreated

Figure 6 | MPs enhance tumour cell susceptibility to chemotherapy. (a) MPs decreased the efflux of drugs in H22 cells. H22 tumour cells were incubated with $\mathrm{H} 22$ cell-derived MPs for $12 \mathrm{~h}$, then treated with $1 \mu \mathrm{g} \mathrm{ml}{ }^{-1}$ doxorubicin. After $6 \mathrm{~h}$, the supernatant was replaced with the fresh medium for another $6 \mathrm{~h}$ culture. The drug efflux by tumour cells was evaluated by flow cytometry and presented as the decrease of MFl. Data were combined from four reproducible experiments. Bars correspond to mean \pm s.d. (b) MPs increased the sensitivity of $\mathrm{H} 22$ cells to drugs. $\mathrm{H} 22$ tumour cells were with or without the pretreatment of MPs and then incubated with different concentrations of MTX. After $6 \mathrm{~h}$, the cells were washed and continued another $16 \mathrm{~h}$ culture. Apoptosis was determined by flow cytometry. Ten thousand events were collected for this analysis. Representative FACS profiles are shown on the left and the combined data from four reproducible experiments are shown on the right. Bars correspond to mean \pm s.d. ${ }^{\star} P<0.05$, compared with control.

However, MPs strikingly inhibited this decrease by MFI from 1,299 to 1,086 (Fig. 6a). Moreover, the simultaneous addition of MPs and doxorubicin also impeded the decrease of MFI from 1,259 to 788 (Fig. 6a), suggesting that MPs might prevent the efflux of chemotherapeutic drug by tumour cells. In line with this result, we found that pretreatment of $\mathrm{H} 22$ tumour cells by MPs enhanced MTX-induced tumour cell apoptosis (Fig. 6b). Therefore, tumour cell-derived MPs were deemed capable of impeding drug efflux, leading to increased tumour cell sensitivity to chemotherapeutic agents.

MPs deliver drugs to solid tumour via intravenous injection. Although MPs were shown to effectively deliver drugs to local peritoneal tumours, it still remained to explore whether MPs were capable of delivering chemotherapeutic drugs to solid tumours. For this purpose, mice were subcutaneously inoculated with $\mathrm{H} 22$ cells. When tumour growth reached $5 \times 5 \mathrm{~mm}^{2}$ in size (5 days), mice were treated with MTX-packaged MPs via tail vein injection. After 7 days continuous injections, tumour growth was shown to be suppressed, compared with the control groups (Fig. 7a).
Moreover, PKH26-conjugated MPs were i.v. injected to $\mathrm{H} 22$ tumour-bearing mice, and tumour was removed for fluorescence detection $4 \mathrm{~h}$ later. We found that MPs could be selectively recruited to the tumour site (Fig. $7 b, c$ ), suggesting that MPs may deliver chemotherapeutic drugs to solid tumours via the circulatory system. We also evaluated the influence of circulating MPs on coagulation. The pro-coagulant state of the mice was assessed after injection of MPs at different time points. We found that the prothrombin time, activated partial thromboplastin time and fibrinogen were not altered by MP injection (Supplementary Fig. S13).

Artificial nanoparticles, such as liposome-packaging drugs, may have similar drug effects as tumour cell-derived MPs. MPs, derived from $1 \mathrm{mg} \mathrm{ml}^{-1}$ paclitaxel-treated $5 \times 10^{6} \mathrm{H} 22$ tumour cells, and $60 \mu \mathrm{g}$ liposome-paclitaxel generated a comparable cytotoxicity to H22 cells (Supplementary Fig. S14). However, a tenfold increase in dosage applied in vivo resulted in different influences on mice weight. Six hundred micrograms liposomepaclitaxel caused a marked weight loss. Even $300 \mu \mathrm{g}$ also negatively affected mice weight (Supplementary Fig. S14). According to these results, 10 -time MPs or $300 \mu \mathrm{g}$ liposome-paclitaxel were 


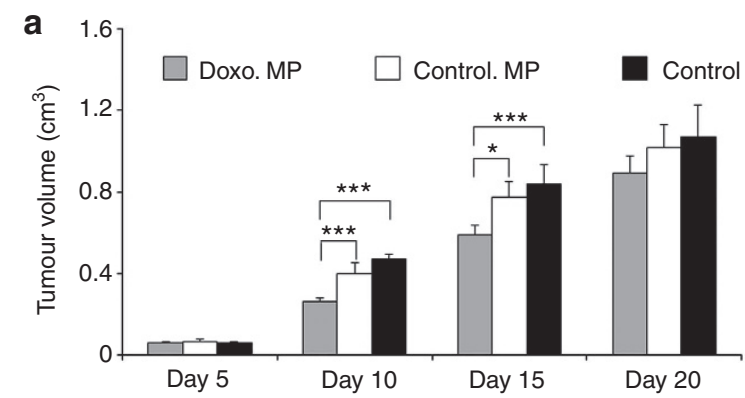

b

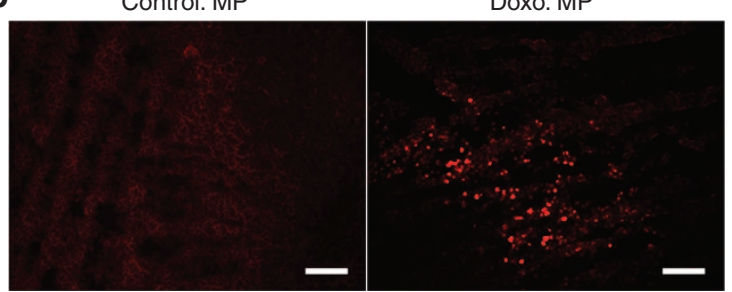

C
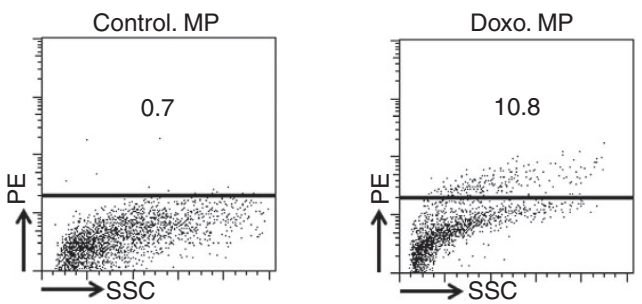

Figure 7 | Intravenouslyly injected MPs deliver chemotherapeutic drugs to solid tumours. (a) BALB/c mice $(n=8)$ were inoculated with $2.5 \times 10^{5}$ $\mathrm{H} 22$ cells subcutaneously. MPs-loaded doxorubicin were injected i.v. daily for 7 days, when tumour reached $5 \times 5 \mathrm{~mm}^{2}$ in size. Tumour growth was monitored $\left(V=a b^{2} / 2\right)$. Data are representative of three independent experiments. Bars correspond to mean \pm s.d. ${ }^{\star} P<0.05$; ${ }^{\star \star \star} P<0.001$. $(\mathbf{b}, \mathbf{c})$ MPs are accumulated in solid tumour site after i.v. injection. PKH26 (red)conjugated MPs were injected to $\mathrm{H} 22$ subcutaneous tumour-bearing mice. After $4 \mathrm{~h}$, tumour tissues were used for the analysis by fluorescence microscope (b). Scale bar, $100 \mu \mathrm{m}$. Ten thousand isolated tumour cells were collected for flow cytometric analysis of PKH26-positive population (c)

i.v. injected to $\mathrm{H} 22$ tumour-bearing mice once per day for 7 days. Although the liposome-paclitaxel treatment inhibited tumour growth, the injection of MPs resulted in higher treatment efficiency (Supplementary Fig. S14).

Actin filaments affect the release and uptake of MPs. To better understand drug-packaging MP-mediated tumour cell killing, the mechanism involved in tumour cell release and uptake of MPs was investigated. The cytoskeleton has important roles in cellular endocytosis and exocytosis ${ }^{23-26}$, leading to the possible requirement of cytoskeletal proteins for the release and uptake of MPs by tumour cells. When $\mathrm{H} 22$ cells were treated with cytochalasin D, an inhibitor of F-actin polymerization, actin filament formation was inhibited, resulting in decreased MP release, induced by ultraviolet irradiation (Fig. 8a). Furthermore, when $\mathrm{H} 22$ cells were treated with blebbistatin, the inhibition of actin filament motility also led to decreased MP release (Fig. 8a). When PKH-26-stained H22 cells, after treatment with cytochalasin D or blebbistatin, were incubated with CFSE-labelled MPs, to determine the uptake of MPs by tumour cells, an unexpected increase in the uptake of MPs by $\mathrm{H} 22$ tumour cells were found (Fig. 8b, c). Similar results were obtained from A2780 tumour cells. It is perhaps safe, therefore, to conclude from these findings that myosin II-triggered, actin filament-generated tension might mediate the release of MPs by tumour cells, whereas a soft microfilament cytoskeleton is perhaps more suitable for MP uptake. Whether this uptake is mediated through endocytosis was also investigated. The endo/lyosome tracker was used to merge the fluorescence of MPs. The result, however, did not show colocalization (Supplementary Fig. S15). In parallel, the endoplasmic reticulum tracker and Golgi tracker were also used for the detection. Similarly, MPs appeared not to interact with endoplasmic reticulum or Golgi (Supplementary Fig. S15). These data suggest that tumour cells take up MPs independent of endocytosis.

\section{Discussion}

The biggest limitation of anticancer chemotherapy lies in its adverse effects ${ }^{27,28}$. To resolve this problem, innovative approaches to deliver chemotherapeutic agents are needed. As the carrier to deliver drugs, MPs have unique advantages: first, MPs are formed from cellular membranes, making them therefore much safer and self-friendlier; second, the preparation of drug-packaging MPs are very simple and easily manipulated; and third, packaging MPs with drugs is a general process and not restricted by physicochemical properties of drugs. The data gathered in this study reveal another critical feature of MP delivery. The use of MPs for the packaging and delivery of chemotherapeutic drugs reduces much of the toxicity of such drugs. The reasons for this advantage may be multiple and not reducible to one simple explanation. Physiological capillary gaps are around 5-8 nm (ref. 29), which prevents 100-1,000 nm MPs from reaching normal tissues and causing damage. Moreover, MPs were found to be very stable and resistant to detergent Triton X-100 consistent with previous reports that lipid rafts might be the main membrane component of MPs ${ }^{30,31}$. However, more important for the purposes of this paper it promises simple effective storage of drugs and innocuous therapeutic interventions in dealing with tumours. Therefore, MPs may well represent a new and more patient friendly approach to deliver chemotherapeutic agents.

Recent studies highlight that lymphocytes, neutrophils, NK cells and even tumour cells can live temporarily within tumour cells, a phenomenon called cell cannibalism or cell-eat-cell ${ }^{32,33}$. Therefore, it might be easy for tumour cells to take up MPs, even though the detailed mechanisms remain unclear. Intriguingly, this uptake is not mediated through endocytosis pathways, so that how MPs release chemotherapeutic molecules within tumour cells is still elusive. Furthermore, regardless of the homology between MPs and tumour cells, it is inevitable that MPs will be taken up by phagocytes, such as macrophages ${ }^{15,34,35}$. This, however, might actually be beneficial to cancer treatment, because tumour-associated macrophages have very important roles in tumour development by promoting neoangiogenesis, remodelling tumour microenvironment and dampening the immune response to tumours ${ }^{36-39}$. In this study, we observed that peritoneal macrophages took up drug-packaging MPs and then died. Whether and how such killing of tumour-associated macrophages synergizes with the killing of tumour cells by drug-packaging MPs to generate better therapeutic effects is currently under study.

Peritoneal neoplasia can originate de novo from the peritoneal tissues as primary tumours ${ }^{40,41}$. However, in most cases, it is derived from the invasion of adjacent tumours or metastasis of remote tumours ${ }^{42,43}$. Although the peritoneal metastasis of colon, liver and pancreatic cancers is not common, clinical ovarian cancer is almost always accompanied by peritoneal metastasis when diagnosed $^{44,45}$. In the present study, drug-packaging MPs 

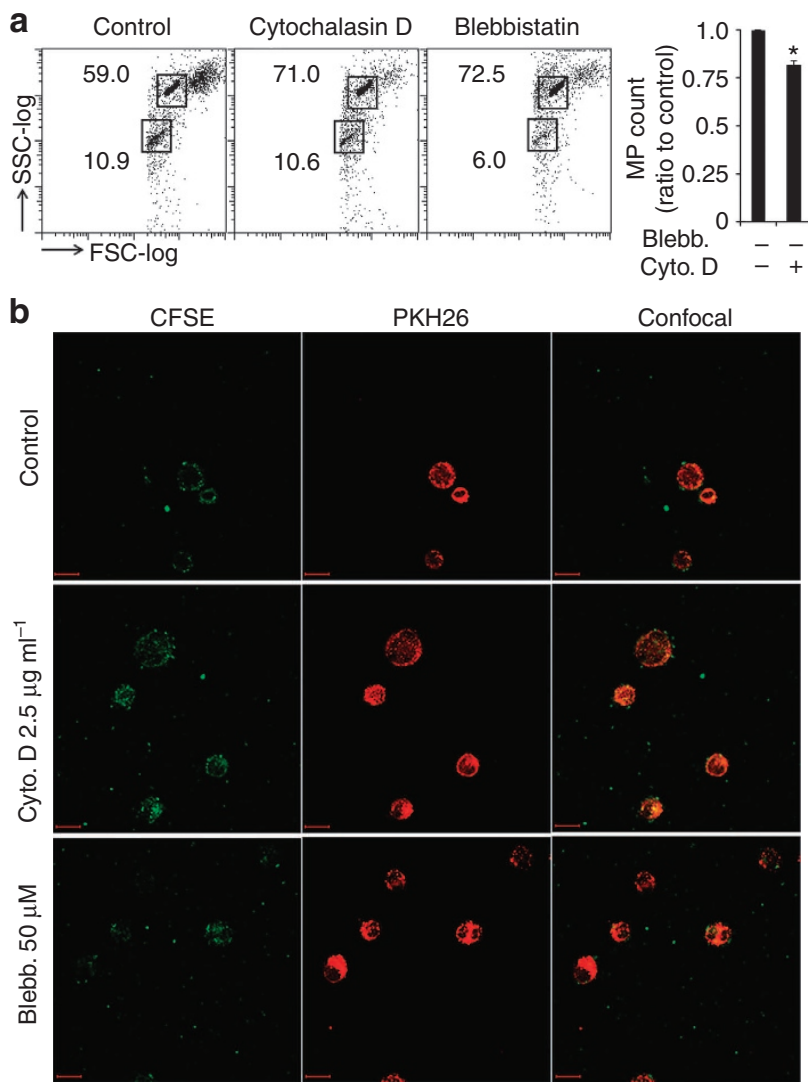

C
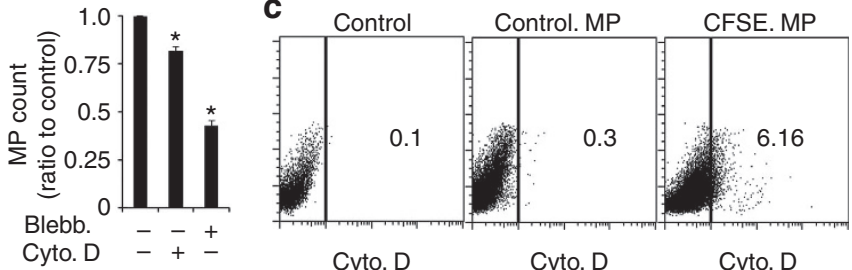

$1.25 \mu \mathrm{g} \mathrm{ml}^{-1} \quad 2.5 \mu \mathrm{g} \mathrm{ml}^{-1} \quad 5 \mu \mathrm{g} \mathrm{ml}^{-1}$

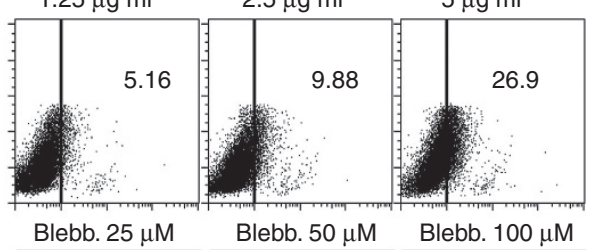

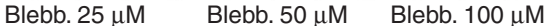
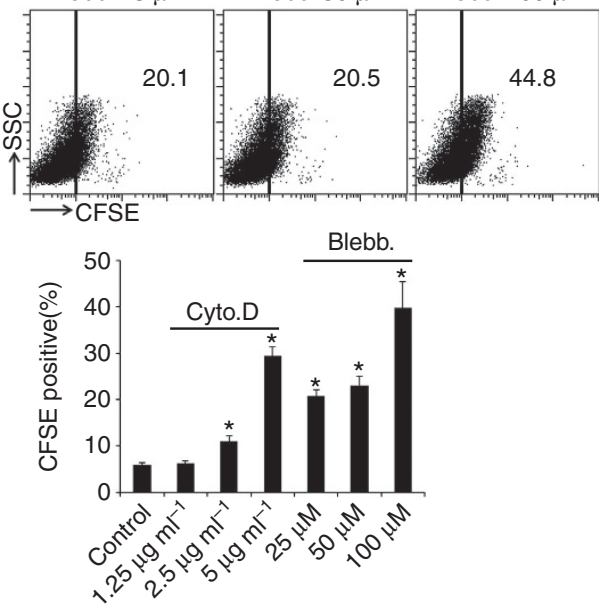

Figure 8 | Actin filaments are involved in release and uptake of MPs. (a) Actin filaments were required for the release of MPs. H22 cells were incubated with cytochalasin D or blebbistatin. After $5 \mathrm{~h}$, cells were washed and irradiated with ultraviolet B. After $24 \mathrm{~h}, \mathrm{MPs}$ in the supernatants were isolated and counted by flow cytometry with polystyrene Latex beads $(3 \mu \mathrm{m})$ as standard (left). The dots in the upper and lower box were generated from standard beads $(3 \mu \mathrm{m})$ and MPs, respectively. The right shown was the combined reproducible data $(n=4)$. Bars correspond to mean \pm s.d. ${ }^{\star} P<0.05$, compared with control group. (b,c) PKH-26 (red)-stained H22 tumour cells were treated with or without different concentration of cytochalasin D or blebbistatin for $5 \mathrm{~h}$, and after the drugs were washed away cells were incubated with CFSE (green)-labelled MPs. After $16 \mathrm{~h}$, cells were harvested and observed under confocal microscope (b) or analysed by flow cytometry (c). Scale bar, $10 \mu \mathrm{m}$. Data are representative of three reproducible independent experiments. Bars correspond to mean \pm s.d. ${ }^{*} P<0.01$, compared with control group. In this figure, 10,000-30,000 events were collected for flow cytometric analysis.

were used to treat peritoneal cancers inoculated with either murine hepatocarcinoma or human ovarian cancer tumour cells. Striking therapeutic efficiencies were observed, in the form of total inhibition of tumour growth in part tumour-bearing mice, even when the packaged drug quantity and the doses of administered MPs were not optimal. H22 cells grow very quickly in the peritoneal cavity, which results in the observed ascites on day 5 and peaked on day 8 or 9 , then maintaining this level owing to space limitations. The single MTX treatment has therapeutic effect only at the beginning, which delays the visible ascites 1 or 2 days, but the ascites came back soon. This very malignant tumour model is chosen in order to emphasize the efficiency of MP-based therapeutics. On the other hand, the difference between normal $(5-8 \mathrm{~nm})$ and tumour capillary permeability $(100-780 \mathrm{~nm})^{29,46,47}$ implies that MPs might be used to deliver drugs to solid tumours by blood flow. This study additionally provides evidence that the delivery of chemotherapeutic to solid tumours by MPs is feasible via direct intravenous injections. Although MPs were found to migrate to the tumour site and be taken up by tumour cells after i.v. injection, the complex and intricate dynamics of such drugpackaging MPs in the blood stream still remains to be elucidated.

Previous works by Jain and colleagues ${ }^{46}$ have demonstrated that the increases in tumour vascular permeability form the basis for nanoparticle extravasation and drug delivery. Recently, works by Dass and colleagues ${ }^{48}$ have shown that chitosan-based delivery systems are efficient for cancer therapy. Along with these studies, current advances in nanotechnology have produced synthetic nanoparticles to encapsulate and release a pre-programmed diversity of therapeutic measures against cancers $1,2,4,49-51$. These artificial materials are, however, known to often induce immune responses, leading to minor or even serious adverse effects ${ }^{3-7}$. Furthermore, nanoparticles range in size from 20 and $50 \mathrm{~nm}$ (refs 2,49), limiting the number of chemotherapeutic molecules that can be packaged. Besides, polymeric micelle systems generally suffer from poor water-soluble drug-incorporation efficiencies. This is because of the small size and hence large surface area of drugs, which promote drug loss into the aqueous phase during particle formation. In contrast, water-soluble drugs are ideal for MPs packaging. As natural self-components, MPs do not induce autoimmunity and range in size from 100 to $1,000 \mathrm{~nm}$, guaranteeing the efficacy of MPs as therapeutic vector to package needed and sufficient enough therapeutic agents. More importantly, this present study indicates that MPs, as natural biomaterials, possess unique merits, such as domino-like killings, where drug-packaging MPs can trigger the formation of new drug-packaging MPs after entering into tumour cells, and inhibiting the efflux of chemotherapeutic drug by tumour cells. 
The latter has important implications for cancer therapy with regard to multidrug resistance ${ }^{52,53}$. This study does not identify or map the exact pathways through which MPs impede the efflux of chemotherapeutic drugs. However, one possibility is that, owing to their compatibility to tumour cell membranes, MP membranes might be integrated into tumour cell membranes, resulting in the blockage of drug-efflux pumps. Further study is required to clarify this.

In summary, the data in this study clearly show that tumour cell-derived MPs, by virtue of their biological formation and subsequent biochemical features, can be used as a carrier to deliver therapeutic agents to tumour cells, leading to effective tumour cell killing with reduced adverse effects. This study may open a new aspect of MP biology and may have discovered a new way for chemotherapeutic drug delivery in cancer therapy.

\section{Methods}

Mice and cell lines. Female BALB/c and BALB/c-SCID mice, 6- to 8-week-old, were purchased from Centre of Medical Experimental Animals of Hubei Province (Wuhan, China) for studies approved by the Animal Care and Use Committee of Tongji Medical College. Murine hepatocarcinoma cell line H22 and human ovarian cancer cell line A2780 were purchased from China Centre for Type Culture Collection (CCTCC, Wuhan, China), and cultured according to the guidelines given.

Generation and isolation of MPs. Tumour cells were treated with chemotherapeutic drug MTX, hydroxyl camptothecin or cisplatin, and then exposed to ultraviolet irradiation (UBV, $300 \mathrm{~J} \mathrm{~m}^{-2}$ ) for $1 \mathrm{~h}$. After $12 \mathrm{~h}$, supernatants were used for MP isolation as described before ${ }^{16,17}$. Briefly, supernatants were first centrifuged for $10 \mathrm{~min}$ at $600 \mathrm{~g}$ to get rid of cells and then centrifuged for $2 \mathrm{~min}$ at $14,000 \mathrm{~g}$ to remove debris. At last, the supernatant was further centrifuged for $60 \mathrm{~min}$ at $14,000 \mathrm{~g}$ to pellet MPs. The pellets were washed three times and resuspended in culture medium for the following experiments.

MP counting. A flow cytometry-based method was used to count the number of MPs. After centrifugation, the MPs were suspended with PBS that was prefiltered through $0.1 \mu \mathrm{m}$ filter and passed through $1 \mu \mathrm{m}$ filter to further exclude background noise or nonspecific events. The MPs mixed evenly with $3 \mu \mathrm{m}$ latex beads (LB-30, Sigma, St Louis, MO) with a known number. For flow cytometric analysis, $0.8 \mu \mathrm{m}$ deep-blue dyed-latex beads (L1398, Sigma) were first used for gating and voltage adjustment, as such beads are fluorescent and can be detected on FL4 channel. When the mixture was analysed by flow cytometry, each LB30 bead formed a dot in the gate of the large-size population. If 10,000 counts of LB30 were collected, the number of MP can be calculated with formula: $N=10,000 \times($ MP percentage/LB30 percentage).

Transmission electron microscope. MPs were passed through $1 \mu \mathrm{m}$ filter and fixed at room temperature for $60 \mathrm{~min}$ with $4 \%$ paraformaldehyde in $0.01 \mathrm{M}$ PBS After washing with PBS, the preparations were postfixed in $1 \%$ OsO4 (Taab) for $30 \mathrm{~min}$. After rinsing with distilled water, the pellets were dehydrated in graded ethanol, including block staining with $1 \%$ uranylacetate in $50 \%$ ethanol for $30 \mathrm{~min}$, and embedded in Taab. After overnight polymerization at $60{ }^{\circ} \mathrm{C}$ and sectioning for EM, the ultrathin sections were analysed with a JEM1010 electron microscope (JEOL, Japan)

Assay of MPs packaging chemotherapeutic agents. Doxorubicin, a red-fluorescent chemotherapeutic drug, was used to treat H22 or A2780 tumour cells. The released MPs were isolated and observed under a two-photon fluorescent microscope (LSM 710 and ConfoCor 3 systems, Carl Zeiss, Germany) to confirm the formation of MPs packaging chemotherapeutic agents.

High-performance liquid chromatography. The concentration of chemotherapeutic drug in MPs was measured by HPLC. Briefly, H22 tumour cell-derived, doxorubicin-packaging MPs were processed by lysis buffer, proteinase K, phenylmethylsulphonyl fluoride and DNase I according to previous description ${ }^{54}$. The HPLC system consisted of a 1525 Binary HPLC Pump, a 717 Plus Autosampler and a 2475 Multi-Wavelength Fluorescence Detector (Waters Corporation, Milford, CT). Chromatography was performed on a column $\left(4.6 \times 150 \mathrm{~mm}^{2}\right.$, particle size $5 \mu \mathrm{m}$ ). The effluents were monitored at an excitation wave length of $480 \mathrm{~nm}$ and an emission wave length of $560 \mathrm{~nm}$ at $40^{\circ} \mathrm{C}$. Detection and integration of chromatographic peaks was performed using Empower 2 software (Waters Corporation).
Cytotoxicity assay of drug-packaging MPs. Drug-packaging MPs were prepared and added to the cultured tumour cells. The cells were observed under a microscope at different time points. In some cases, cells were collected and stained with annexin $\mathrm{V}$ and propidium iodide for apoptosis detection by a flow cytometer.

Labelling of MPs. Isolated MPs were labelled with a red-fluorescent cell linker (PKH26, Sigma) according to the manufacturer's protocol.

Flow cytometry. A BDTM LSR II flow cytometer (BD) was used to do the flow cytometric analysis of the MPs in samples. The instrument settings and MP gating were adopted from previous works ${ }^{55}$. Samples were diluted in 1:30 with $1.2-\mu \mathrm{m}$ pore size membrane-filtered PBS in order to reduce background event numbers. A microbead of $3 \mu \mathrm{m}$ in diameter (Sigma-Aldrich) was used to select optimal instrument settings and MP gate. Total event counts of MPs were determined within the MP gate.

Animal model and MP treatment protocol. $1 \times 10^{5} \mathrm{H} 22$ murine hepatocarcinoma tumour cells (BALB/c background) were i.p. injected into $B A L B / c$ mice. Seven days later, the growth of $\mathrm{H} 22$ tumour cells formed hepatocarcinoma ascites. To treat this peritoneal tumour, $2 \mathrm{mg}$ MTX was added to $2 \times 10^{7} \mathrm{H} 22$ tumour cells in $2 \mathrm{ml}$ culture medium and the prepared MTX-packaging MPs were then administered to one mouse per packaged MPs. On day 2 after H22 tumour cell inoculation, mice were received MTX-packaging MPs by i.p. injection once per day for 5 days.

For the human ovarian cancer murine peritoneal model, BALB/c-SCID mice were i.p. injected with $5 \times 10^{6} \mathrm{~A} 2780$ human ovarian cancer tumour cells. On day 2 after the inoculation, MPs generated from $2 \times 10^{7}$ A2780 cells treated with cisplatin $\left(300 \mu \mathrm{g} \mathrm{ml}^{-1}\right)$ were i.p. injected to mouse once per day for 5 days. After day 14 , an additional treatment was administered once per day for 5 days. On day 30 , half the mice were killed for tumour detection and the left mice were fed for the long-term survival study.

In selected cases, drug-packaging MPs and paclitaxel-liposome were i.v. injected to mice. Paclitaxel-liposome, which was approved by the State Food and Drug Administration of China (No. H20030357), was purchased from Nanjing Si Ke Pharmaceutical Co., Ltd. (Nanjing, China) as freeze-dried powder in glass vials containing $30 \mathrm{mg}$ of active drug.

Hoechst 33342 uptake assay. Isolated MPs treated with or without $0.5 \%$ Triton X-100 were incubated with Hoechst 33342 for $12 \mathrm{~h}$. MPs were isolated again resuspended in $30 \mu \mathrm{l}$ PBS buffer. Suspensions were smeared on a glass slide and photographed under a fluorescence microscope.

Assay of tumour cells taking up MPs in vitro. CFSE-labelled H22 cells treated with UBV irradiation $\left(300 \mathrm{~J} \mathrm{~m}^{-2}\right)$ were cultured for $24 \mathrm{~h}$. MPs were isolated from the supernatant, and then incubated with PKH 26 -stained H22 cells for $20 \mathrm{~h}$. Cells were observed by two-photon confocal microscope or analysed by flow cytometry.

Peritoneal H22 tumour cell isolation. $3 \times 10^{5} \mathrm{H} 22$ tumour cells were i.p. injected into BALB/c mice. Peritoneal tumour cells were isolated at different time points. Briefly, peritoneal cells were harvested and centrifugated. After lysis of RBC, cells were incubated on ice for $20 \mathrm{~min}$ and then spun down at 500 revolutions per minute. for $1 \mathrm{~min}$. This process was repeated twice and the spun cells were further incubated for $2 \mathrm{~h}$ to get rid of adhesive cells. The cells left were used as H22 tumour cells.

Mouse primary hepatocyte isolation. Mouse primary hepatocytes were isolated from BALB/c mice using a two-step collagenase perfusion as described previously ${ }^{56}$. The viable hepatocyte population was further purified by a Percoll gradient centrifugation ${ }^{57}$. Hepatocytes were resuspended and seeded onto collagencoated plates at $2 \times 10^{5}$ cells per well in a 6-well plate in Williams' E medium (Invitrogen) with $10 \% \mathrm{FBS}$, insulin $\left(0.5 \mu \mathrm{g} \mathrm{ml}{ }^{-1}\right.$, Sigma), dexamethasone $(50 \mathrm{nM}$, Sigma), streptomycin $\left(0.1 \mathrm{mg} \mathrm{ml}^{-1}\right)$ and penicillin $\mathrm{G}\left(100 \mathrm{U} \mathrm{ml}^{-1}\right)$ at $37^{\circ} \mathrm{C}$ and under $5 \% \mathrm{CO}_{2}$

Assaying second and third generations of MPs. H22 tumour cells were treated with $250 \mu \mathrm{g} \mathrm{ml}^{-1}$ doxorubicin to prepare the first generation of MPs. Such doxorubicin-packaging MPs were incubated with fresh $\mathrm{H} 22$ tumour cells. After $6 \mathrm{~h}$, cells were washed and irradiated with UBV $\left(300 \mathrm{~J} \mathrm{~m}^{-2}\right)$. After another $24 \mathrm{~h}$, the released MPs packaging doxorubicin were detected with two-photon confocal microscope or flow cytometry and called the second generation of MPs. In the same way, the third generation of MPs were prepared.

Statistics analysis. Results were expressed as mean values \pm s.d. and interpreted by repeated-measure analysis of variance or Kaplan-Meier analysis. Differences were considered to be statistically significant when the $P$-value was $<0.05$. 


\section{References}

1. Jain, R. K. \& Stylianopoulos, T. Delivering nanomedicine to solid tumors. Nat. Rev. Clin. Oncol. 7, 653-664 (2010).

2. Adair, J. H., Parette, M. P., Altinoğlu, E. I. \& Kester, M. Nanoparticulate alternatives for drug delivery. ACS Nano 4, 4967-4970 (2010).

3. Lammers, T., Hennink, W. E. \& Storm, G. Tumour-targeted nanomedicines: principles and practice. Br. J. Cancer 99, 392-397 (2008).

4. Shvedova, A. A., Kagan, V. E. \& Fadeel, B. Close encounters of the small kind: adverse effects of man-made materials interfacing with the nano-cosmos of biological systems. Annu. Rev. Pharmacol. Toxicol. 50, 63-88 (2010).

5. Hu, Y. L. \& Gao, J. Q. Potential neurotoxicity of nanoparticles. Int. J. Pharm. 394, 115-121 (2010).

6. Lewinski, N., Colvin, V. \& Drezek, R. Cytotoxicity of nanoparticles. Small 4, 26-49 (2008).

7. Barnard, A. S. Nanohazards: knowledge is our first defence. Nat. Mater. 5, 245-248 (2006)

8. György, B. et al. Detection and isolation of cell-derived microparticles are compromised by protein complexes resulting from shared biophysical parameters. Blood 117, 39-48 (2011).

9. Ratajczak, J., Wysoczynski, M., Hayek, F., Janowska-Wieczorek, A. \& Ratajczak, M. Z. Membrane-derived microvesicles: important and underappreciated mediators of cell-to-cell communication. Leukemia 20, 1487-1495 (2006).

10. Wolf, P. The nature and significance of platelet products in human plasma. $\mathrm{Br}$. J. Haematol 13, 269-288 (1967).

11. Hugel, B., Martínez, M. C., Kunzelmann, C. \& Freyssinet, J. M. Membrane microparticles: two sides of the coin. Physiology 20, 22-27 (2005).

12. Mause, S. F. \& Weber, C. Microparticles: protagonists of a novel communication network for intercellular information exchange. Circ. Res. 107, 1047-1057 (2010)

13. Théry, C., Ostrowski, M. \& Segura, E. Membrane vesicles as conveyors of immune responses. Nat. Rev. Immunol. 9, 581-593 (2009).

14. Boilard, E. et al. Platelets amplify inflammation in arthritis via collagendependent microparticle production. Science 327, 580-583 (2010).

15. Distler, J. H. et al. The release of microparticles by apoptotic cells and their effects on macrophages. Apoptosis 10, 731-741 (2005).

16. Barry, O. P., Pratico, D., Lawson, J. A. \& FitzGerald, G. A. Transcellular activation of platelets and endothelial cells by bioactive lipids in platelet microparticles. J. Clin. Invest. 99, 2118-2127 (1997).

17. Tang, K. et al. Microparticles mediate enzyme transfer from platelets to mast cells: a new pathway for lipoxin A4 biosynthesis. Biochem. Biophys. Res. Commun. 400, 432-436 (2010).

18. Shedden, K., Xie, X. T., Chandaroy, P., Chang, Y. T. \& Rosania, G. R. Expulsion of small molecules in vesicles shed by cancer cells: association with gene expression and chemosensitivity profiles. Cancer Res. 63, 4331-4337 (2003).

19. Ullal, A. J. et al. Microparticles as antigenic targets of antibodies to DNA and nucleosomes in systemic lupus erythematosus. J. Autoimmun. 36, 173-180 (2011).

20. Simons, K. \& Gerl, M. J. Revitalizing membrane rafts: new tools and insights. Nat. Rev. Mol. Cell. Biol. 11, 688-699 (2010).

21. Riganti, C. et al. Liposome-encapsulated doxorubicin reverses drug resistance by inhibiting p-glycoprotein in human cancer cells. Mol. Pharm. 8, 683-700 (2011).

22. Rajendran, L., Knölker, H. J. \& Simons, K. Subcellular targeting strategies for drug design and delivery. Nat. Rev. Drug. Discov. 9, 29-42 (2010).

23. Collins, A., Warrington, A., Taylor, K. A. \& Svitkina, T. Structural organization of the actin cytoskeleton at sites of clathrin-mediated endocytosis. Curr. Biol. 21, 1167-1175 (2011)

24. Soldati, T. \& Schliwa, M. Powering membrane traffic in endocytosis and recycling. Nat. Rev. Mol. Cell Biol. 7, 897-908 (2006).

25. Nightingale, T. D. et al. Actomyosin II contractility expels von Willebrand factor from Weibel-Palade bodies during exocytosis. J. Cell Biol. 194, 613-629 (2011).

26. Masedunskas, A. et al. Role for the actomyosin complex in regulated exocytosis revealed by intravital microscopy. Proc. Natl Acad. Sci. USA 108, 13552-13557 (2011).

27. Bermejo, C. et al. Neoadjuvant chemotherapy followed by aggressive surgical consolidation for metastatic penile squamous cell carcinoma. J. Urol. 177, 1335-1338 (2007).

28. Atallah, E. et al. Establishment of baseline toxicity expectations with standard frontline chemotherapy in acute myelogenous leukemia. Blood 110, 3547-3551 (2007).

29. Dvorak, A. M. et al. The vesiculo-vacuolar organelle (VVO): a distinct endothelial cell structure that provides a transcellular pathway for macromolecular extravasation. J. Leukoc. Biol. 59, 100-115 (1996).

30. Davizon, P., Munday, A. D. \& López, J. A. Tissue factor, lipid rafts, and microparticles. Semin. Thromb. Hemost. 36, 857-864 (2010)
31. Del Conde, I., Shrimpton, C. N., Thiagarajan, P. \& López, J. A. Tissue-factorbearing microvesicles arise from lipid rafts and fuse with activated platelets to initiate coagulation. Blood 106, 1604-1611 (2005).

32. White, E. Entosis: it's a cell-eat-cell world. Cell 131, 840-842 (2007).

33. Lugini, L. et al. Cannibalism of live lymphocytes by human metastatic but not primary melanoma cells. Cancer Res. 66, 3629-3638 (2006).

34. Greenberg, S. \& Grinstein, S. Phagocytosis and innate immunity. Curr. Opin. Immunol. 14, 136-145 (2002).

35. Litvack, M. L., Post, M. \& Palaniyar, N. IgM promotes the clearance of small particles and apoptotic microparticles by macrophages. PLoS One 6, e17223 (2011).

36. Munari, F. et al. Tumor-associated macrophages as major source of APRIL in gastric MALT lymphoma. Blood 117, 6612-6616 (2011).

37. Movahedi, K. et al. Different tumor microenvironments contain functionally distinct subsets of macrophages derived from Ly6C(high) monocytes. Cancer Res. 70, 5728-5739 (2010).

38. Pollard, J. W. Trophic macrophages in development and disease. Nat. Rev. Immunol. 9, 259-270 (2009)

39. Hagemann, T. et al. "Re-educating" tumor-associated macrophages by targeting NF-kappaB. J. Exp. Med. 205, 1261-1268 (2008).

40. Villa, R. et al. Multiple mechanisms of telomere maintenance exist and differentially affect clinical outcome in diffuse malignant peritoneal mesothelioma. Clin. Cancer Res. 14, 4134-4140 (2008).

41. Miselis, N. R., Wu, Z. J., Van Rooijen, N. \& Kane, A. B. Targeting tumorassociated macrophages in an orthotopic murine model of diffuse malignant mesothelioma. Mol. Cancer Ther. 7, 788-799 (2008).

42. Takei, Y., Takigahira, M., Mihara, K., Tarumi, Y. \& Yanagihara, K. The metastasis-associated microRNA miR-516a-3p is a novel therapeutic target for inhibiting peritoneal dissemination of human scirrhous gastric cancer. Cancer Res. 71, 1442-1453 (2011).

43. Chaffer, C. L. \& Weinberg, R. A. A perspective on cancer cell metastasis. Science 331, 1559-1564 (2011).

44. Lengyel, E. Ovarian cancer development and metastasis. Am. J. Pathol. 177, 1053-1064 (2010).

45. Tan, D. S., Agarwal, R. \& Kaye, S. B. Mechanisms of transcoelomic metastasis in ovarian cancer. Lancet Oncol. 7, 925-934 (2006).

46. Monsky, W. L. et al. Augmentation of transvascular transport of macromolecules and nanoparticles in tumors using vascular endothelial growth factor. Cancer Res. 59, 4129-4135 (1999).

47. Roberts, W. G. \& Palade, G. E. Neovasculature induced by vascular endothelial growth factor is fenestrated. Cancer Res. 57, 765-772 (1997).

48. Tan, M. L., Choong, P. F. \& Dass, C. R. Review: doxorubicin delivery systems based on chitosan for cancer therapy. J. Pharm. Pharmacol. 61, 131-142 (2009).

49. Ali, I. et al. Advances in nano drugs for cancer chemotherapy. Curr. Cancer Drug Targets 11, 135-146 (2011).

50. Murphy, E. A. et al. Nanoparticle-mediated drug delivery to tumor vasculature suppresses metastasis. Proc. Natl Acad. Sci. USA 105, 9343-9348 (2008).

51. Dass, C. R., Contreras, K. G., Dunstan, D. E. \& Choong, P. F. Chitosan microparticles encapsulating PEDF plasmid demonstrate efficacy in an orthotopic metastatic model of osteosarcoma. Biomaterials 28, 3026-3033 (2007).

52. Higgins, C. F. Multiple molecular mechanisms for multidrug resistance transporters. Nature 446, 749-757 (2007)

53. Fletcher, J. I., Haber, M., Henderson, M. J. \& Norris, M. D. ABC transporters in cancer: more than just drug efflux pumps. Nat. Rev. Cancer 10, 147-156 (2010).

54. Hillegass, J. M. et al. Increased efficacy of doxorubicin delivered in multifunctional microparticles for mesothelioma therapy. Int. J. Cancer 129, 233-244 (2011)

55. Combes, V. et al. In vitro generation of endothelial microparticles and possible prothrombotic activity in patients with lupus anticoagulant. J. Clin. Invest 104, 93-102 (1999).

56. Ji, Y. et al. Hepatic scavenger receptor BI promotes rapid clearance of high density lipoprotein freecholesterol and its transport into bile. J. Biol. Chem. 274, 33398-33402 (1999)

57. Lee, P., Peng, H., Gelbart, T. \& Beutler, E. The IL-6- and lipopolysaccharideinduced transcription of hepcidin in HFE-, transferrin receptor 2-, and beta 2 microglobulin-deficient hepatocytes. Proc. Natl Acad. Sci. USA 101, 9263-9265 (2004).

\section{Acknowledgements}

We acknowledge Soundny (Sheng-Qi-An) Biotech (Wuhan, China), the Funds for National Basic Research Programme of China (2012CB932500) and International Cooperation and Exchange of the National Natural Science Foundation of China (30911120482). We thank Dr Yonghong Wan (McMaster University) for helpful discussion and assistance in editing this article, and Dr Wei Dai and Mr Yehua Han (Institute of Basic Medical Sciences, Chinese Academy of Medical Sciences) for technical support on electron microscopy. 


\section{Author contributions}

B.H. conceived the project. K.T., Y.Z., H.Z., P.X., J.L., J.M., M.L. and D.L. performed the experiments. F. K., G.-X.S., G.Z., Z.-H.F., D.Y. and B.H. analysed the results. K.T. and B.H. wrote the manuscript.

\section{Additional information}

Supplementary Information accompanies this paper on http://www.nature.com/ naturecommunications
Competing financial interests: B.H. was supported by Soundny (Sheng-Qi-An) Biotech. The other authors declare no competing financial interests.

Reprints and permission information is available online at http://npg.nature.com/ reprintsandpermissions/

How to cite this article: Tang, K. et al. Delivery of chemotherapeutic drugs in tumour cell-derived microparticles. Nat. Commun. 3:1282 doi: 10.1038/ncomms2282 (2012). 